\section{Thermal and structural analysis of a fuel storage tank under an adjacent pool fire}

\author{
Susana N. Espinosa, ${ }^{1}$ Rossana C. Jaca, ${ }^{1}$ \\ Luis A. Godoy ${ }^{2}$ \\ ${ }^{1}$ Department of Mechanics, Faculty of \\ Engineering, National University of \\ Comahue, Neuquén; ${ }^{2}$ Institute for \\ Advanced Studies in Engineering and \\ Technology, Science Research Council of \\ Argentina (CONICET) and National \\ University of Córdoba, Argentina
}

\begin{abstract}
This work reports the modeling and computational implementation of heat transfer processes that take place from a source tank to a target tank in a tank farm, focusing on the thermal field that develops at the target tank. Pool fire with gasoline burning is modeled at the source, in which the flame is represented by a two-layer solid flame model. A rigorous heat transfer model is implemented together with a Computational Fluid Dynamics model for the fuel storage. This process yields the temperature field in the target tank. Such thermal fields are subsequently employed as input in a structural analysis of the target tank to compute displacements and stresses and to assess possible structural damage. For the case studied, the results show that a steady-state process is reached in less than an hour, with temperatures in the order of $400^{\circ} \mathrm{C}$ at elevations above the fuel level stored in the target tank, whereas much lower temperatures are computed on the zone in contact with fuel. Displacement jumps are seen to occur at the fuel level and at the junction between the cylinder and a fixed roof.
\end{abstract}

\section{Introduction}

The storage of oil and fuel in refineries and oil depots is currently carried out in tank farms, which may be located in isolated sites, such as in the Patagonia region, or close to cities, such as in areas close to New Orleans affected by Hurricane Katrina. Fire and explosions have been identified as the most frequent causes of damage and collapse of such tanks, with the aggravating situation that fire may extend from one tank to another, thus leading to a domino effect. ${ }^{1}$

There are many possible sources of fire in a tank farm, and one cause of great con- cern to engineers is when fire develops at the top of one tank where vaporized fuels burn in what is known as pool-fire. This class of fire has been observed in many large-scale accidents, including those at Buncefield, UK, in 2005, and at Bayamon, Puerto Rico, in 2009.

Modeling such events is less than a simple task and requires performing an adequate representation of the flame at the source, radiation and convection through air and heating of the target structure, which in this case is a steel tank located in the vicinity of the pool fire. Furthermore, a target tank containing fuel develops more complex heat transfer scenarios. A number of researchers have addressed parts of this process, so that empirical data and correlations have been proposed based on controlled fire tests. Many different studies ${ }^{2-9}$ report flame characterizations in terms of fuel properties, pool diameter, and wind speed. Such data has been included as part of heat transfer computer simulations to estimate thermal effects on adjacent tanks and available time before a flame is extinguished.

Regarding the fire source, the solid flame model represents a flame as a vertical (or inclined) cylinder having the same diameter as the source tank and with a geometry in elevation given by empirical methods. ${ }^{2-6}$ It has been observed that combustion of light fuels, such as liquefied petroleum gas and liquefied natural gas, produces a clear flame with temperatures in the range between $1000^{\circ} \mathrm{C}$ and $1500^{\circ} \mathrm{C}$. On the other hand, two zones can be identified in liquid hydrocarbon pool fire: ${ }^{10-12}$ a clear zone develops at the base with a visible flame, and a darker zone at the upper part of the flame, where combustion is less efficient leading to intermittent flames surrounded by dense smoke. Researchers have proposed correlations to estimate flame emissive power; this can be done as an average for the complete flame or by providing local values for clear and dark zones of the flame. ${ }^{7-10}$

Levels of incident radiation affecting neighboring tanks have been reported in the literature; ${ }^{10,13-16}$ however, in only few cases the steady-state temperature field reaching the target tank is available. ${ }^{17-19}$ Assessment of such temperature fields requires performing an energy balance at the target tank that takes into account all heat transfer modes present in this problem, i.e. net radiation received by the steel surface, heat conduction through the steel shell, and convective heat transfer to the fuel stored in the target tank. Results reported in references, ${ }^{17,18}$ were obtained under the assumption that the
Correspondence: Susana N. Espinosa Department of Mechanics, Faculty of Engineering, National University of Comahue, Neuquén Buenos Aires 1400, 8300 Neuquén, Argentina.

Tel.: +54.299.4490300.488.

E-mail: susana.espinosa@fain.uncoma.edu.ar

Key words: Computational fluid dynamics; Flame model; Heat transfer analysis; Pool fire; Storage tanks; Structural analysis.

Contributions: SNE carried out the literature review on the heat transfer problem, developed the thermal model, and implemented its computational simulation; RCJ developed the structural model, and implemented its computational simulation; LAG contributed to the conception and design of the work, and performed preliminary studies of the structural analysis. All the authors gave final approval of the version to be published.

Conflict of interest: the authors declare no potential conflict of interest.

Funding: funding for this research was provided by Universidad Nacional del Comahue, Argentina, and by CONICET, Argentina (through grants PIP 0126 and grant to UEIDIT).

Support for this research has been provided by the Science and Technology Research Council of Argentina, CONICET, by a grant on "Vulnerability of infrastructure and physical media associated with fuel storage and transportation".

Conference presentation: part of this paper was presented at the 4th Ibero-Latin American Congress on Fire Safety ( $4^{\circ}$ CILASCI), 2017 Oct 9-11, Recife, Brazil.

Received for publication: 12 December 2017 Revision received: 6 August 2018.

Accepted for publication: 6 August 2018 .

This work is licensed under a Creative Commons Attribution 4.0 License (by-nc 4.0).

C Copyright S.N. Espinosa et al., 2018

Licensee PAGEPress, Italy

Fire Research 2018; 2:48

doi:10.4081/fire.2018.48

fuel stored remains at ambient temperature; this may be a good approximation in empty tanks but not for tanks with liquid fuels due to their large capacity to store thermal energy. This paper explores the transient heat transfer process from a pool fire at a source tank to a second tank located close to the source. Interest focuses on the temperature field developed at the target tank and the potential structural consequences caused by such thermal loads. 


\section{Materials and Methods}

\section{Towards temperature estimates on the target shell}

The specific scenario considered in this work includes two tanks having the same geometry; fire is assumed to occur in one of them, here identified as the source tank, and interest focuses on the temperature field that develops in the second tank, identified as the target tank. The flame in the source tank causes heat radiation towards the target tank. In this case study, the separation between tanks (shell to shell) is one diameter, the source tank is opened at the top, whereas the target tank has a fixed conical roof. It is assumed that the target tank contains fluid stored which modifies the temperature field in the walls.

A sequential analysis is performed in this work, in which temperatures are first obtained on the target tank by means of heat transfer analysis plus Computational Fluid Dynamics (CFD) to account for convection in the fluid stored in the target tank. A second stage is performed by means of a structural analysis of the target tank under a thermal load defined in the first stage; the structural analysis should be capable of modeling geometrically non-linear behavior.

\section{Flame geometry}

The evaluation of heat radiation in this problem requires use of a realistic flame model. Pool fire models have been extensively employed in the literature to represent a flame. ${ }^{12-19}$ The flame is characterized by turbulent diffusion which is controlled by buoyancy forces burning on top of a vaporized fuel pool with negligible initial moment. ${ }^{14}$ Within the context of this work, the flame is represented by a cylinder having the same diameter as the source tank and with a height which is determined by means of empirical procedures. Evaluation of flame height is usually carried out by means of an empirical work originally proposed by Thomas, ${ }^{2}$ and supplemented by experimental data reported by Babrauskas, ${ }^{5}$ for a large number of combustible fuels; such methodology has been employed in other studies. ${ }^{14,15,17-19}$ The flame height $H_{f}$ is estimated in this work following a correlation in terms of flame diameter, $D_{f}$, and fuel burning rate per unit area, $m$ (Eq. 1):

$$
\begin{aligned}
& H_{f} / D_{f}=42\left(m^{*}\right)^{0.61} \\
& m^{*}=\frac{m}{\rho_{o} \sqrt{g D_{f}}} \\
& m=m_{x}\left(1-\operatorname{Exp}\left(-k \beta D_{f}\right)\right)
\end{aligned}
$$

where $m^{*}$ is a normalized burning rate; $r_{o}$ is the density of air at ambient temperatures; $g$ is the standard gravity; and the constants for gasoline were taken from Babrauskas ${ }^{5}$ as $m_{x}$ $=0.055 \mathrm{~kg} / \mathrm{m}^{2} \mathrm{~s}$ and $k \beta=2.1 \mathrm{~m}^{-1}$.

The height of the clear flame, denoted by $L_{c}$, is measured from the top of the source tank. Evaluation of $L_{c}$ in this work is carried out by means of an expression due to Pritchard and Binding (Eq. 2) ${ }^{7}$

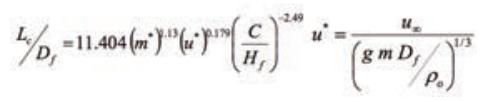

where $u^{*}$ is a non-dimensional wind speed; $u_{\infty}$ is the wind speed measured at $9 \mathrm{~m}$ above ground level; and $C / H$ the ratio of carbon atoms to hydrogen atoms present in the fuel.

In the experimental correlation proposed by Pritchard and Binding, ${ }^{7}$ the flame starts at the top of the source tank and, in the absence of wind, it raises vertically. However, as fire progresses the flame may extend throughout the complete elevation of the source tank, so that heat radiates from the base. To consider the worst scenario, the flame is assumed in this work to start from ground level, so that the height of the clear flame is given by $(L c+H)$.

The idealized flame geometry is shown in Figure 1, together with the tank geometry. For the present case study, the geometry of the tanks is given by a diameter $D=11.44$ m, cylinder height $H=11.44 \mathrm{~m}$, with a conical roof with elevation of $1 \mathrm{~m}$. Thus, the total height of the structure is $12.44 \mathrm{~m}$. The tanks are separated by a distance of one diameter, $d=1 D$. The level of liquid gasoline inside the target tank is $H / 2$. Properties of steel and air were computed in terms of
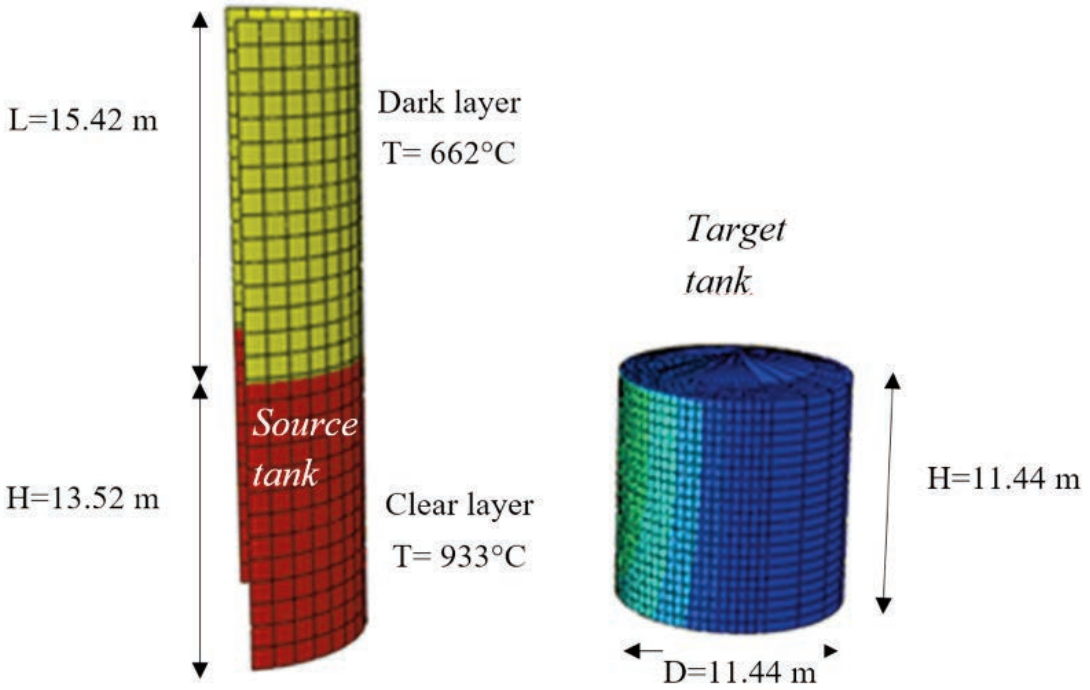

Figure 1. Geometric characteristics of flame, source tank and target tank. temperature. Properties of liquid gasoline were taken from the literature,,$^{13}$ and introduced as data into the CFD model.

\section{Flame emissive power}

The rate at which radiation is emitted per unit area of the surface flame, known as flame emissive power, $E$, is estimated using a two-layer solid model, in which heat is assumed to radiate from the surface of a solid cylinder. This is known as Two-Layer Solid Flame Model. ${ }^{7}$ The solid has a diameter $D$ and it is assumed to radiate from two zones. The clear flame zone (with height equal to $L c$ ) has a maximum emissive power, $E_{\max }$, with experimental values for gasoline combustion that range between $120 \mathrm{~kW} / \mathrm{m}^{2}$ and $170 \mathrm{~kW} / \mathrm{m}^{2},{ }^{13-16}$ whereas $E$ decreases in the upper zone as a consequence of a less efficient combustion. Estimates in this work follow the work of Mudan and Croce, ${ }^{9}$ and assume a constant emissive power of the clear flame given by $E_{\max }=140 \mathrm{~kW} / \mathrm{m}^{2}$; this value corresponds to the emissive power of a black body that radiates at $1250 \mathrm{~K}$, the temperature of combustion of gasoline. The average value, $E_{a v}$, for the upper part in the form (Eq. 3):

$$
E_{a v}=E_{\max } \operatorname{Exp}[-0.12 D]+E_{\text {soot }}(1-\operatorname{Exp}[-0.12 D])
$$

with $E_{\text {soot }}=20 \mathrm{~kW} / \mathrm{m}^{2}$ for soot. The exponential terms account for darkening effects and depend on the source tank diameter.

\section{Effective flame temperature}

Only part of the emitted radiation reaches the target tank due to the relative position of source and target tanks, which is taken into account with the View Factor, and to a 
lesser extent due to the atmospheric transmissivity which lowers the energy radiated by the flame as a consequence of the presence of water vapor and carbon dioxide in the atmosphere.

View Factors are internally computed by the ABAQUS code based on the position of each element in the target tank and each element in the solid flame model, so that they depend i) on the shortest distance between the specific element on the target tank and the specific element on the flame, and ii) on the angle of inclination of the element in the target tank with respect to the element in the flame. Thus, each finite element has a different View Factor for each finite element employed in the discretization of the flame.

Atmospheric transmissivity, $t$, is evaluated following Wein equation, ${ }^{20}$ in terms of distance from the source, relative humidity of air, and water saturation pressure at ambient temperature. However, whereas the View Factor is calculated by a finite element model, atmospheric transmissivity is taken into account by estimating an Effective Mean Temperature for each flame zone, ${ }^{18} T_{e f}$. This is an equivalent flame temperature which produces an average emissive power, $\tau E f_{a v}$ (Eq. 4):

$$
T_{e f}=\left(\frac{\varepsilon_{f} \sigma T_{a}^{4}+\tau E f_{a v}}{\varepsilon_{f} \sigma}\right)^{0.25}
$$

where $\varepsilon_{f}$ is the flame emissivity; $\sigma$ is the Stefan/Boltzmann constant $\left(\sigma=5.67 \times 10^{-8}\right.$ $\left.\mathrm{W} / \mathrm{m}^{2} \mathrm{~K}^{4}\right)$; $t$ is the atmospheric transmissivity; and $T_{a}$ is the ambient temperature given in ${ }^{\circ} \mathrm{K}$.

The estimated values of emissive power, transmissivity, and effective mean temperature of clear and dark flame layers are given in Table 1.

\section{Heat transfer model}

The net energy exchanged at the target tank is evaluated using an energy balance to account for the radiation exchange between flame-tank-environment, radiation through internal air (assuming that liquid gasoline is opaque to radiation), heat transfer by natural convection to internal and external air and towards fuel stored in the target tank, and conduction through the steel shell.

The convective heat flow $q$ " between the tank surface at temperature $T_{s}$ and fluid at temperature $T_{\infty}$, was computed using Newton's model ${ }^{20}$ (Eq. 5):

$$
q_{c o n v}^{\prime \prime}=h_{\text {air }}\left(T_{s}-T_{\infty}\right)
$$

The average convection coefficient, $h_{\text {air }}$, is internally evaluated by ABAQUS for each finite element by introducing the convection coefficient as a function of temperature given by the correlation due to Churchill and $\mathrm{Chu}^{20}$ for natural convection on vertical plates with height $H$. This correlation may also be applied to vertical cylinders of height $H$ in this case because the boundary layer thickness is much less than the cylinder diameter. ${ }^{20}$

Values of the film coefficient $h$ and thermal diffusivity $\alpha$ are evaluated from the non-dimensional number of Nusselt (average) $\left(\overline{N u_{H}}\right)$; Rayleigh $\left(R a_{H}\right)$; and Prandt $(P r)$. Other required fuel properties are the thermal expansion coefficient, $\beta$; viscosity, $v$; thermal conductivity, $K$; density, $\rho$; and specific heat at constant pressure, $c_{p}$. (Eq. 6).

$$
\begin{aligned}
& \overline{N u_{H}}=\left\{0.825+\frac{0.387 R a_{H}^{1 / 6}}{\left[1+(0.492 / P r)^{9 / 16}\right]^{8 / 27}}\right\}^{2} \\
& R a_{H}=g \beta(T s-T \infty) H^{3} /(v \alpha) \\
& P r=v / \alpha \\
& \alpha=K /\left(\rho . c_{p}\right) \\
& h=\overline{N u_{H}} K / H
\end{aligned}
$$

The fluid properties are computed at film temperature $T_{\text {fim }}=\frac{T s+T \infty}{2}$, where $T_{s}$ is the surface temperature, and $T_{x}$ is the fluid temperature. The air film coefficient has been introduced in the model as a function of the temperature of the target tank surface, $T_{s}$, to account for its variation in time. The natural convection within liquid gasoline was obtained by solving the Navier-Stokes equations using CFD by means of a co-sim- ulation with the heat transfer model.

Because the target tank is a very thin steel shell, the conductive resistance to heat transfer is negligible in comparison with convective resistances on both sides of the shell; therefore, no distinction is made in the following discussion between external and internal temperature surfaces.

\section{Computational model}

The complete model described in previous sections was implemented using the general-purpose finite element program ABAQUS. ${ }^{21}$

To evaluate the temperature field on the target tank, a heat transfer module was used together with a CFD model. The specific approach is known as co-simulation using conjugate heat transfer in which ABAQUS/Standard is coupled with ABAQUS/CFD to simultaneously obtain thermal effects in the structure and in the fluid stored in the target tank. The CFD analysis considers heat transfer by natural convection in the liquid fuel and was carried out to determine the temperature field on the shell wall of the target tank in contact with liquid gasoline; this is the first time this approach has been followed in the context of thermal analysis of oil storage tanks.

For the ABAQUS/Standard study, a non-stationary analysis was carried out using triangular (DS6, six-node) and quadratic (DS8, eight-node) heat transfer elements. The ABAQUS/CFD study was performed using linear (FC3D4, four-node) elements. A sequential analysis was carried out to evaluate the structural response of the shell under the previously defined temperatures. Shell elements S8R and STRI65 were used to compute displacements and stresses.

\section{Structural analysis under thermal loads}

In the sequential analysis, the temperature field obtained as explained in Section 2 was used to perform a structural analysis of the target tank. The tank is considered as a cylindrical shell simply supported at the base and with a fixed roof on top. The geometry of the tank is given by $D=11.44 \mathrm{~m}$ and cylinder height $H=D$. Based on API specifications, ${ }^{22}$ a shell thickness of $6.4 \mathrm{~mm}$

Table 1. Estimated flame parameters.

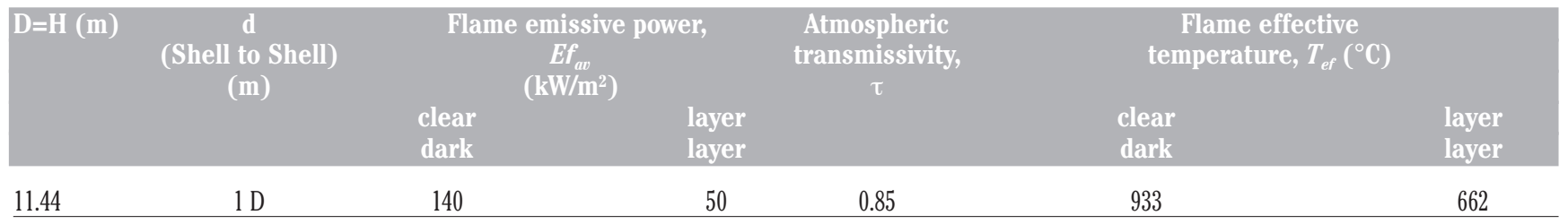


(1/4") was adopted. The conical roof has a 1 $m$ maximum elevation with respect to the cylinder top. The shell material is A36 steel, with a modulus of elasticity assumed as a temperature decreasing function following Eurocode 3, ${ }^{23-24}$ whereas a constant Poisson ratio $v=0.3$, was adopted for the calculations.

A Geometrically Non-linear Analysis (GNA) was performed to evaluate shell deformations. Discretization of the shell as a structure employed six-node triangular (STRI65) and eight-node quadrilateral (S8R) elements. Based on convergence studies, a mesh with 1458 elements was found to be adequate for present purposes. The load was assumed as a temperature field based on the thermal analysis previously performed.

Conical roofs are not self-supported structures and require the use of a support structure with radial and ring rafters. To simplify the study, details of the roof structure have not been included in this model and an equivalent roof thickness is used to estimate the stiffening influence of such structure. This approach has been used by most researchers in this field. ${ }^{17,24}$ As a consequence of that, the present results are not directly transferable to real tanks in a quantitative way but they rather reflect the expected qualitative behavior of conical roof tanks. Based on the work by Burgos et $a l .,{ }^{24}$ the recommended value of roof thickness equal to three times the shell thickness has been adopted.

\section{Results and Discussion}

As stated before, results for a single configuration are reported in this work in order to illustrate the type of behavior that is to be expected from the present modeling approach.

Results of the CFD analysis are shown in Figure 2 for flame radiation arriving from the left side of the graphs. The pressure field is plotted in Figure 2A, whereas the velocity vectors are shown in Figure 2B. When the fluid is in contact with the hot metal surface of the tank, the buoyancy forces are higher than the viscous forces, thus inducing the hot liquid to flow upwards on the left side (as shown by red and green arrows in Figure 2B), whereas the zone of cold liquid flow downwards on the righthand side. A circular motion of the liquid is induced and the mixture of internal streams which are typical of natural convection occur. The temperatures in the liquid tend to a uniform distribution; however, the mean temperature in the fluid increases unless the flame is extinguished.
Profiles of non-steady temperatures are shown in Figure 3 at four nodes located on the shell surface directly facing the flame. Nodes A, B, and C are located on the shell surface above the fluid level (dry surface), while node D is located on the shell surface in contact with the liquid gasoline (wet surface). Temperatures in $\mathrm{A}, \mathrm{B}$, and $\mathrm{C}$ rise rapidly, reaching stationary values in the order of $400^{\circ} \mathrm{C}$ in a time slightly less than an hour. On the other hand, node D increases temperature at a lower rate, and always stays below the temperatures reached at the dry surface. The liquid acts by cooling the wet wall of the tank, as a consequence of the high heat capacity of liquids in general as compared with gases, which are above the fuel level.

Because of its multi-component nature, gasoline increases up to $60-70^{\circ} \mathrm{C}$, depending on its specific components. Beyond this temperature, evaporation of the light com-

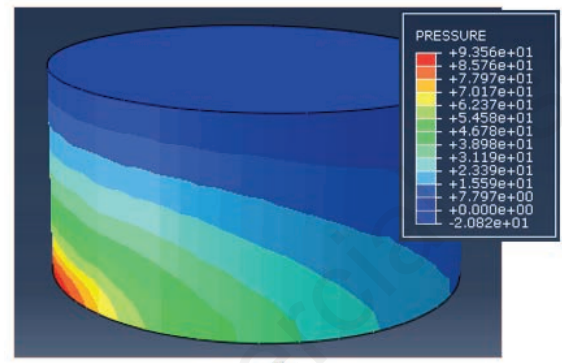

A ponents of gasoline starts, thus initiating a fractional distillation of fuel starts, in which phase changes modify the temperature distribution on the wet surface of the tank (node D) and modify the level of stored fuel. This complex behavior has not been taken into account in the model; this is why the temperature profile for node $\mathrm{D}$ has been plotted only up to $80^{\circ} \mathrm{C}$. This temperature is considered as mean temperature of the liquid film for the stationary analysis, because evaporation in the zone adjacent to the surface and the increasingly vigorous mixing of the internal fluid will significantly reduce the slope of curve D over time.

The possibility of fire extending to other tanks depends on a number of possible isolated or simultaneous events, including vapor accumulation in the space between the fuel and the roof. If the velocity of vapor generation is higher than the velocity of evacuation thought relief valves, an

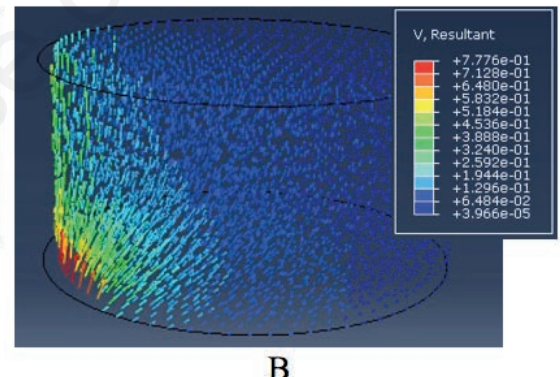

B
Figure 2. (A) Pressure field and (B) velocity field in the fluid stored in the target tank, induced by natural convection.

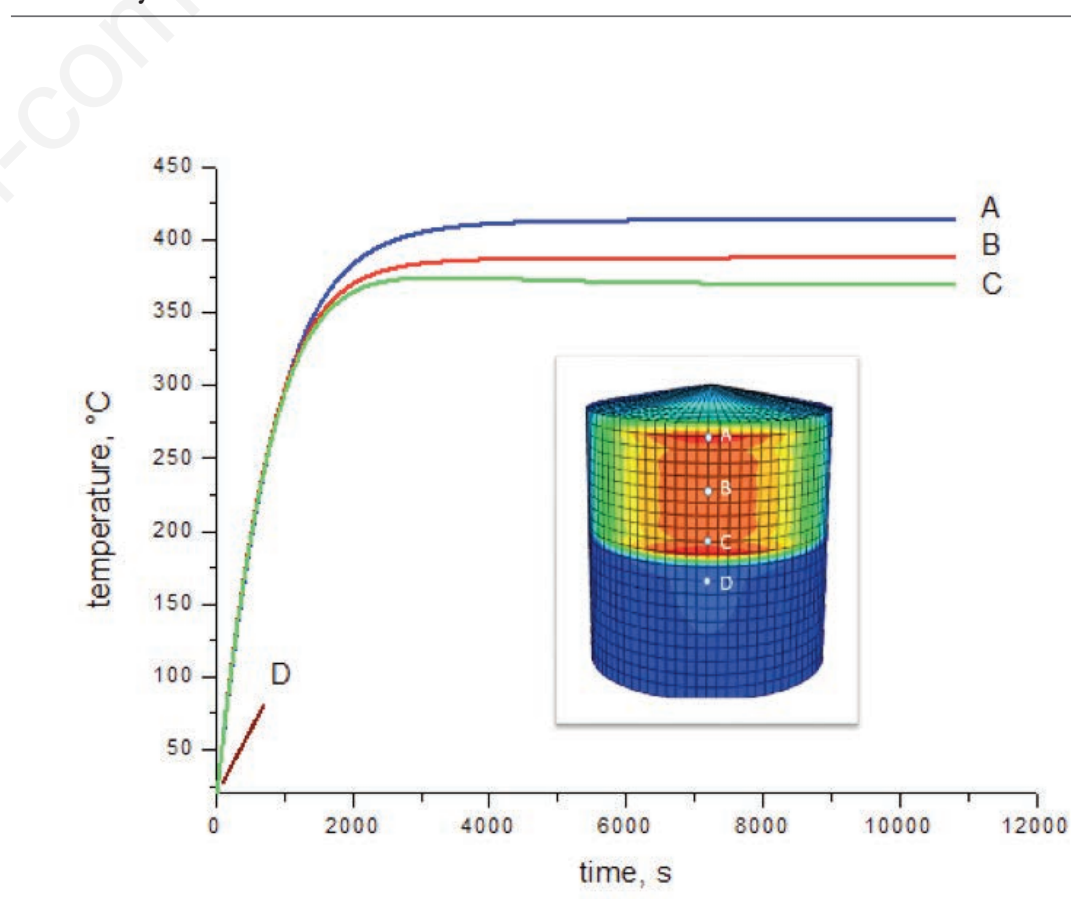

Figure 3. Transient thermal profile for nodes A, B, C and D on the hottest vertical surface. 
explosion could occur due to an increase of internal pressure. On the other hand, if a mixture air-fuel forms within the flammability limits of gasoline, a new flame could initiate in contact with the upper (hot) part of the tank walls, as stated by Mansour. ${ }^{13}$ This follows from the trends shown in Figure 3 for points A, B and C. A new flame can also be produced by a source of ignition, such as a spark caused by static electricity. Finally, there is a possibility of structural collapse with a subsequent fuel spill.

Strains and displacements caused by the high temperatures acting on the shell were next computed. The shell response is plotted in Figure 4 for a tank which is filled up to $0.5 \mathrm{H}$. The temperature distribution in Figure 4A for the shell in contact with fuel is below $100^{\circ} \mathrm{C}$; however, higher temperatures up to $400^{\circ} \mathrm{C}$ are computed for the top part of the shell above fuel level. Figure 4B shows that larger displacements occur in the top regions of the tank.

A sharp change in displacements is seen to occur in the displacement profile in elevation, shown in Figure 5. A change from $10 \mathrm{~mm}$ to $30 \mathrm{~mm}$ (for a shell and roof with thickness equal to $6.4 \mathrm{~mm}$ ) occurs between wet and dry zones of the shell wall. There is a second sharp change in displacements at the intersection between cylinder and roof, and this effect largely depends on the assumed roof thickness. This second sharp variation may eventually cause detachment of the roof, and this incident would leave the tank in a vulnerable situation prone to receive burning ashes..$^{13}$

Results for two different roof thickness configurations ( $t=t s$ and $t=3 t s$, where $t s$ is the thickness of the cylinder shell) are compared in Figure 5B. The roof stiffness has a local effect on temperature distributions and does not significantly affect the cylindrical shell of the tank.

\section{Conclusions}

A detailed model has been presented in this work regarding thermal loads on thinwalled vertical oil/fuel storage tanks. The thermal loads are assumed to be caused by an adjacent fire in which heat is radiated to the target structure. As a heat source, the work considers a flame burning in an adjacent tank, here identified as the source tank. Notice that fuel is only burning in the source tank, where there is a flame, under the assumption that all fuel stored in the source tank is burning. In the target tank, on the other hand, there is an increase in the fuel temperature but no flame appears.

A single configuration has been investigated, with both tanks having height $\mathrm{H}$ to diameter $\mathrm{D}$ ratio $\mathrm{H} / \mathrm{D}=1$, and radius to thickness ratio $\mathrm{R} / \mathrm{ts}=1787$. For this problem, an energy balance was implemented to account for heat transfer combined with a CFD model for the fluid stored inside the target tank. The tank was assumed to contain fuel up to half the cylinder height.

Rather than representing structural details of the tank, the present study accepts some simplifications currently employed in the literature, by which the roof structure is substituted by an equivalent increased roof thickness based on an equivalence between inertia of the exact and simplified models. ${ }^{24}$

Some conclusions may be drawn from the study: i) Results of the present heat transfer simulations show temperature fields with high values occurring above
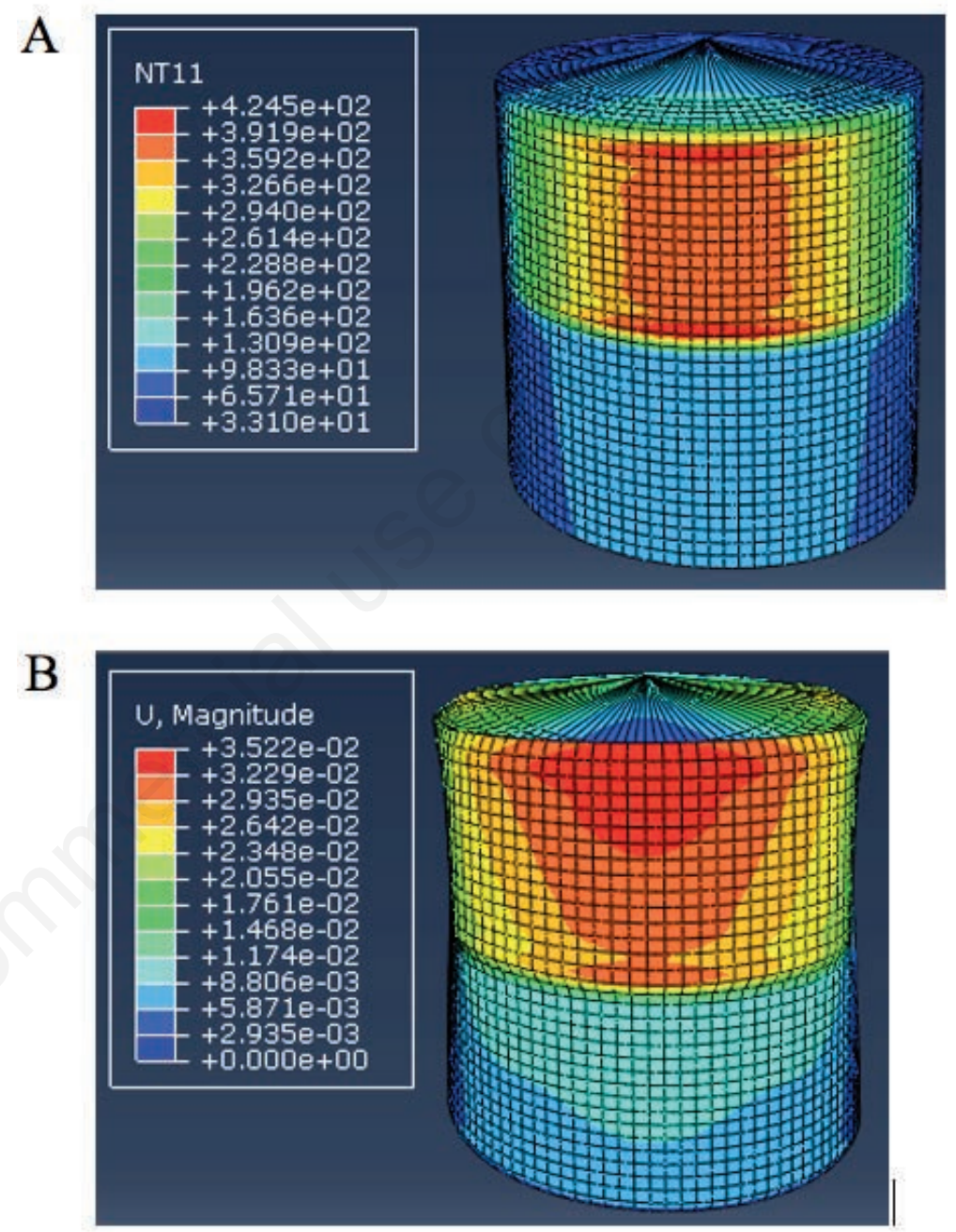

Figure 4. Results for fuel level up to $H / 2$, roof thickness: $t=t s$. (A) Temperature distribution $\left[{ }^{\circ} \mathrm{C}\right]$; and $(\mathrm{B})$ Displacements $[\mathrm{m}]$.

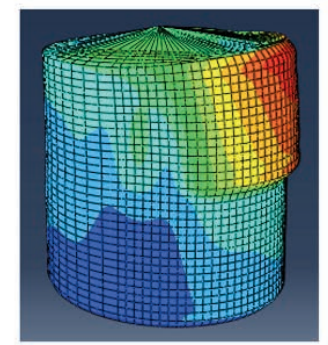

A

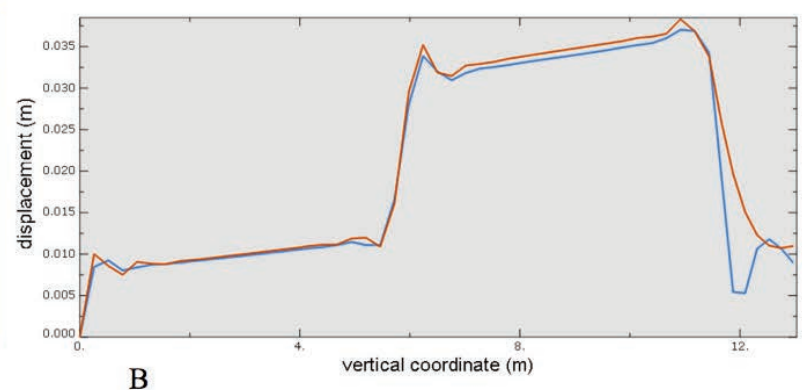

B

Figure 5. Thermal displacements: (A) Side view; (B) Comparison for two different roof thicknesses, $t=t s(-)$ and $\mathrm{t}=3$ ts $(-)$. 
fluid level (in the dry zone) and significantly smaller values of temperature being computed below fluid level (in the wet zone); ii) Temperatures increase in time until a steady state is reached in the upper zone of the tank. For the present case studied, the steady state is reached in less than one hour. Although this time depends on several variables, this study indicates that there is a short time available before the highest temperatures are reached in neighboring tanks. The risk of damage of the structure is considerably reduced if the flame is extinguished before one hour; iii) Sharp changes in out-of-plane displacements are computed between dry and wet zones, and at the intersection between dry and roof zones. In terms of structural response, it may be seen from the curves that a reduction in displacements between four to five times occurs between the roof junction and the fluid level.

Within the context of the present work, in which emphasis is placed on the modeling of the flame and heat analysis, the authors did not explore buckling and imperfection sensitivity of the target tank. This has been done in previous works ${ }^{17,19,24-27}$ and is by a now a better-known field of research.

\section{References}

1. Reniers G, Cozzani V. Domino effects in the process industries. Modeling, prevention and managing. Oxford, UK: Elsevier; 2013.

2. Thomas PH. The size of flames from natural fires. Proceedings of the 9th International Combustion Symposium, Pittsburgh, PA, USA; 1963. pp 844-859.

3. Moorhouse J. Scaling laws for pool fires determined from large scale experiments. IChemE Symposium Series 1982;71:165-79.

4. Heskestad G. Luminous height of turbulent diffusion flames. Fire Safety J
1983;5:103-8.

5. Babrauskas V. Estimating large pool fire burning rates. Fire Technol 1983;19: 251-61.

6. Raj PK. A physical model and improved experimental data correlation for wind induced flame drag in pool fires. Fire Technol 2010;46:579-609.

7. Pritchard, MJ, Binding TM. FIRE2: A new approach for predicting thermal radiation levels from hydrocarbon pool fires. IChemE Symposium Series 1992;130:491-505.

8. Shokri M, Beyler CL, Radiation from larger pool fires. SFPE J Fire Protect Engin 1989;4:141-50.

9. Mudan, KS, Croce PA. Fire hazard calculations for large open hydrocarbon fires. In: SFPE Handbook of Fire Protection Engineering, 1st ed. Quincy, MA: NFPA; 1988. Section 2: pp 45-87.

10. McGrattan KB, Baum HR, Hamins A. Thermal radiation from large pool fires. Nistir 6546. National Institute of Standards and Technology; 2000.

11. Considine M. Thermal radiation hazard ranges from large hydrocarbon pool fires. Safety \& Reliability Directorate. UK Atomic Energy Authority, UKAEA Report N SRD R297; 1984.

12. Beyler CL. Fire hazard calculations for large open hydrocarbon fires. SFPE Handbook of Fire Protection Engineering. New York, NY: Springer; 2002.

13. Mansour KA. Fires in large atmospheric storage tanks and their effect on adjacent tanks. PhD Thesis. Loughborough University, UK; 2012.

14. Rew PJ, Hulbert WG, Deaves DM. Modelling of thermal radiation from external hydrocarbon pool fires. Trans IChemE 1997;75:81-9.

15. Sengupta A, Gupta AK, Mishra IM. Engineering layout of fuel tanks in a tank farm. J Loss Prevent Proc Industr 2011; 24:568-74.

16. Ufuah E, Bailey CG. Flame radiation characteristics of open hydrocarbon pool fires. Proceedings World Congress on Engineering, London, UK; 2011. pp 1952-1958.

17. Liu, Y. Thermal buckling of metal oil tanks subject to an adjacent fire, $\mathrm{PhD}$ Thesis. The University of Edinburgh, UK; 2011.

18. Da Silva Santos F, Landesmann A. Thermal performance-based analysis of minimum safe distances between fuel storage tanks exposed to fire. Fire Safety J 2014;69:57-68.

19. Espinosa SN, Jaca RC. Transferencia de calor entre tanques de combustible expuestos a fuego. Mecánica Computacional 2016;34:135-49.

20. Incropera FP, DeWitt DP. Fundamentals of heat and mass transfer. New York, USA: John Wiley \& Sons; 2002.

21. Abaqus. Simulia. Unified FEA. Dassault Systems. Warwick, Rhode Island, USA; 2006.

22. API 650. Welded steel tanks for oil storage. Washington DC, USA: American Petroleum Institute; 2010.

23. European Committee for Standardization EN 1993-1-2 Eurocode 3: Design of Steel Structures - Part 1-2, General Rules - Structural Fire Design; 2003.

24. Burgos CA, Batista-Abreu JC, Calabró $\mathrm{HD}$, et al. Buckling estimates for oil storage tanks: Effect of simplified modeling of the roof and wind girder. ThinWalled Struct 2015;91:29-37.

25. Pantousa D, Tzavos K, Kefaki MA. Thermal buckling behavior of unstiffened and stiffened fixed-roof tanks under nonuniform heating. J Construct Steel Res 2018;143:162-79.

26. Godoy LA, Batista-Abreu J. Buckling of fixed roof aboveground oil storage tanks under heat induced by an external fire. Thin-Walled Struct 2012;52:90101.

27. Godoy LA. Buckling of oil storage steel tanks: Review of static buckling. ThinWalled Struct 2016;103:1-21. 